\title{
Flipping JACO
}

Mark C. Wilson (University of Auckland, New Zealand), Hendrik van Maldeghem (Ghent University, Belgium), Victor Reiner (University of Minnesota, USA), Christos Athanasiadis (University of Athens, Greece), Akihiro Munemasa (Tohuku University, Sendai, Japan) and Hugh R. Thomas (Université du Québec, Montréal, Canada)

This article is about the conversion of a subscription mathematics journal owned by a large commercial publisher into an independent, open access journal. Mark C. Wilson discusses the background to this and the main editors of the journal describe their impressions and experiences.

\section{Introduction (Mark C. Wilson)}

In July 2017, the four editors-in-chief and the whole editorial board of Journal of Algebraic Combinatorics (JACO) gave notice of their resignation to the publisher, Springer. A new journal with the same editors, Algebraic Combinatorics (ALCO), published by the Centre Mersenne based at the University of Grenoble, was announced almost immediately and began publication in January 2018. What was behind these moves?

MathOA (of which I am a board member) is a foundation (Stichting), set up in the Netherlands in late 2016, dedicated to achieving precisely this kind of outcome, that is, the "flipping" of established mathematics journals to a model known as "Fair Open Access". The five principles behind Fair Open Access are as follows (many more details are available at http://fairopenaccess.org):
1. The journal has a transparent ownership structure and is controlled by and responsive to the scholarly community.

2. Authors of articles in the journal retain copyright.

3. All articles are published open access and an explicit open access licence is used.

4. Submission and publication is not conditional in any way on the payment of a fee from the author or its employing institution, or on membership of an institution or society.

5. Any fees paid on behalf of the journal to publishers are low, transparent and in proportion to the work carried out.

Many existing journals satisfy (more or less!) these five conditions. Some of them are fairly well known (for example, Electronic Journal of Combinatorics and Journal of Computational Geometry). However, many established mathematics journals are owned by large commercial publishers such as Elsevier, Springer, Taylor \& Francis and Wiley. MathOA is engaged in systematically contacting editorial boards of such journals and raising 
money to support flipped journals. The main obstacles in the minds of editors appear to be a fear of loss of quality and reputation, worries about financial stability of open access journals and concerns about the work involved in transitioning to a new publisher. MathOA was established precisely in order to alleviate these concerns.

Some prominent, commercially published journals are owned by learned societies: for example, Communications in Pure and Applied Mathematics (owned by the Courant Institute and published by Wiley), Israel J. Math. (owned by The Hebrew University Magnes Press and published by Springer) and Publications Math. de l'IHES (owned by IHES and published by Springer), and there is some chance of bringing market forces to bear. However, large commercial publishers own the titles of such well known journals as Inventiones Mathematicae, Advances in Mathematics, Journal of Algebra, Journal of Functional Analysis, Journal of Number Theory, Journal of Combinatorial Theory A, Journal of Combinatorial Theory B and Discrete Mathematics. They will not relinquish these names lightly, since trading on the reputation mostly created by others is the basis of their enormous profit margins. Thus, flipping a journal often requires a change of name. With appropriate community buy-in, the reputation of the old journal (which has almost nothing to do with the publisher and everything to do with the authors, reviewers and editors who have contributed) usually transfers quickly to the new (for example, see my basic analysis at https:// mcw.blogs.auckland.ac.nz/2016/10/08/what-happens-tojournals-that-break-away/).

\section{Hendrik Van Maldeghem}

We were first contacted on 26 September 2016 by Mark Wilson as to whether we would consider a "flip". There was some discussion among the editors-in-chief, including Vic Reiner, a former EiC (Editor-in-Chief) who would help us a lot with the flip. We quickly converged to agree with the flip. Our initial concerns were the reputation of the journal and the amicable relationship with Springer that we would put on the line, not yet being that concerned either about funding or about the platform we would be using. On 6 October, we replied to Mark that we all agreed.

One thing that made things easier was that all our contracts, except Hugh's, ended at the same time (31 December 2017). So, canonically, we could start the new journal then. Hugh, who began his work with JACO on 1 January 2017, pulled off a one-year contract, so we could all resign at the same time. Up until April 2017, not much happened except that a major funder suddenly withdrew. However, we were assured that funding would still be no problem so we did not have to worry about this, and we did not. In March 2017, we started composing a letter to the full board to ask them to join us at the new journal and, from that moment on, things felt more serious. So serious, in fact, that I started to have doubts about the reliability of the project. In particular, when we showed the letter that we had composed to send to the editors to Mark, he reacted "not to be over-promising" to the editors. That made me nervous since suddenly and for the first time it seemed that we could not take things for granted. The four of us decided to contact Vic and chat with him. He persuaded us to continue with solid arguments and since then I have had no doubts anymore. It was natural for us to ask Vic to be the interim EiC of the new journal, which we would baptise "Algebraic Combinatorics". In fact, Vic has been a great help at every step of the transition; he was the one we could rely on and, for me, his presence always gave me a feeling of certainty. His determination and energy was very contagious.

Our letter was sent to the editors and then, for me, the work became less. As a non-native English speaker, I preferred not to be involved with the advertising, other PR jobs or helping compose a constitution. I could just focus on the rest of my editorship with JACO.

Around the end of June, we let Springer know that we would not renew our contracts and that was also a difficult moment, if only psychologically. Indeed, we had worked with people like Elizabeth Loew for several years and kept good contact, and so it felt like a betrayal. But we kept things professional and, after all, we were not doing anything illegal. Springer made some modest attempts to keep us on board and change our minds but this did not do any good.

The next thing to confront us was the installation of the new EiC of JACO, who began his duties in October. Ilias Kotsireas is his name. His point of view was completely opposite to ours. For instance, he wanted to send every submitted paper to referees, which, in our opinion, is very inefficient. Soon, one of us (Christos) could no longer deal with Ilias' way of working and quit the team early. I remember that moment was hard since, on the one hand, one wants to show solidarity with a co-editor but, on the other hand, we had a responsibility toward the authors and submitted papers. The three of us (Hugh, Akihiro and I) decided to stay and I wrote a letter of reconciliation to Elizabeth. She appreciated that and we could continue working. But it was very difficult. Ilias was granted the sole right to reject and accept papers. Although we were seriously doing our jobs, by suggesting immediate rejections of some manuscripts, Ilias never followed these suggestions. On the contrary, he sent all manuscripts to reviewers. So, in fact, we gave up after a few weeks in trying to educate the new EiC; after all, it was not our concern anymore. We were cut off from access to the electronic manager a few days earlier than we expected and so our time at JACO had come to a definite end. I was happy to be able to concentrate on the new journal, ALCO. I just hope that the manuscripts at JACO with a pending decision were treated seriously, which I doubt. I wrote a letter to Elizabeth to show my appreciation for her as a person and to let her know that our decisions were, of course, purely professional and that we could part with a positive feeling.

\section{Victor Reiner}

The notion of JACO leaving Springer was not totally new. I was a JACO EiC during 2000-2005 and, around 2004, we had several issues of dissatisfaction surrounding the journal's transition from ownership by Kluwer 
to Springer, and Springer's business practices (including high subscription fees and outrageously high fees for à la carte article purchases). This eventually led the four EiCs to a negotiation with the new Springer representative, Ann Kostant. We entered the negotiation with the support of our editorial board, leaving open the possibility of leaving Springer and following the lead of the successful open access Electronic Journal of Combinatorics. After that negotiation, the four EiCs had differing feelings about whether to stay or leave Springer but in the end we decided to stay.

Fast-forward 13 years to 2017 and the landscape had changed. One of the issues holding us back in 2004 was concern over publication of paper volumes - this no longer seems important. Another issue in 2004 was the service provided by a commercial publisher via its editorial management software - this issue has evaporated through the development of free systems like OJS (Open Journal Systems) or reasonably-priced systems like EditFlow. The nail-in-the-coffin for me was when I was approached by Mark Wilson of MathOA in early September 2016. He told me of MathOA's goal of flipping maths journals and their efforts to get financial support from library consortia to support such moves, along with the legal and technical experience of people at MathOA, such as Johan Rooryck, who had flipped the commercially-owned linguistics journal Lingua to the open access journal Glossa. I eventually suggested that JACO might be a candidate for such a flip and expressed my willingness to work toward it.

From there onward, things went as Hendrik has described. On my end, once I had discussed the possibility of flipping with the four JACO EiCs and they seemed willing, I then mustered the support of the editorial board of the journal. The board took it seriously and there was discussion of alternatives and concerns. In the end, they were willing to follow the will of the EiCs and resign at the same time, on 31 December 2017. Once the EiCs had presented their resignation letter to Springer in June 2017, I and the board presented a joint resignation letter to Springer in July.

Meanwhile, since the JACO EiCs were working for the old journal until the end of the year, I set about starting the new open access journal ALCO, as an interim EiC until the JACO EiCs could take over. Fortunately, Satoshi Murai was available to join me as the second interim EiC of ALCO, with the intention that he would take the place of Christos Athanasiadis as the fourth EiC after 1 January 2018. Satoshi turned out to be a fantastic partner and the two of us began handling the papers that came pouring in. During the journal set-up process, Mark Wilson and Benoît Kloeckner of MathOA were indispensable in helping us examine various options for service providers and publishing structure. Eventually, we decided to use the new Centre Mersenne in Grenoble as a service provider, which has worked out very well. They provide much of the infrastructure, including maintaining a version of the editorial software OJS, hosting the papers on their site, helping us choose a style file for the journal and providing DOIs for papers for almost no cost. Their main charge is for the copy-editing required to fix some authors' articles after they have prepared them in the journal style file, for which they charge the very reasonable price of 7 euros per page (many articles do not need these fixes). Centre Mersenne's service and responses to our questions and concerns have been excellent.

In terms of community support, almost everyone has been behind us - support has been particularly strong among younger mathematicians. In July 2017, I sent a mass email to the algebraic combinatorics community, announcing and explaining the flip and asking people to support ALCO and to stop supporting JACO. As Springer and the new JACO EiC Kotsireas began inviting new names to populate their various editorial and advisory boards, many people told me that they had refused. However, as a few new names appeared on the list of editorial boards posted on the JACO website, I tried to politely explain the situation to these new editors and ask them to consider removing themselves from these boards. Some responded, explaining their reasons, and others did not. Some withdrew from the boards. My hope is that, in the end, the old journal will fade away.

\section{Christos Athanasiadis}

Another of our initial concerns (as far as I remember) was the amount of our time and effort we would have to put into the flip. As it turned out, this was not so bad (mainly thanks to MathOA support) so other editors considering flipping in the future should not be discouraged by this matter.

I was a bit surprised about Springer appointing an EiC without consulting us about his suitability. This showed that they only cared about retaining the journal as their property and not at all about its content or quality. I could not possibly have cooperated and did the right thing for everyone (I believe) in quitting when the chance came up.

My impression is that the procedure was easier than we initially expected (and the publisher had no way to stop it).

\section{Akihiro Munemasa}

Since I became an editor-in-chief in 2000, I have received a lot of respectful words from mathematicians in this area, probably much more than I deserve. It became clear to me that, in addition to daily editorial work, editors are supposed to be decision-makers of what our research area should be aiming for. Let me explain why and what made us leave Springer. Our activity is almost entirely based on our own mathematical interest, at least in the beginning, and the publisher's role was minimal when I started. Around 2004, Springer bought the former publisher Kluwer, so we started working with Springer's editorial office. Also, around the same time, quantitative evaluation of research performance started to prevail; notably, the publisher and editors needed to care about Impact Factors. Springer, as a commercial publisher, worked hard to sell the journal to a larger number of customers. Trying to improve Impact Factors is one thing but packaging with some other journals to increase subscriptions is another. While this behaviour affected our work very little, I started to feel that I was not doing the highest priority work 
for mathematicians. We should have the right to say if a journal is not serving the mathematical community in the best way we could imagine.

However, with a commercial publisher, a journal runs according to their policy and editors are kind of "hired" to run the journal. Instead, editors should work voluntarily based on their own mathematical interest and should choose a publisher that does the job noncommercially.

I might be too optimistic. Increasing use of quantitative measures in research in all disciplines makes people ignore such opinions. Mathematicians might be in a minority by resisting commercial intervention in their research. But I was encouraged to hear that a journal in linguistics had already made a flip before us and this was one of the important reasons that made us think we were making the right move.

\section{Hugh Thomas}

I volunteered to be the contact person for the editorsin-chief in dealing with media inquiries. To get ready for this, we collectively wrote a set of responses to questions we anticipated being asked, which was a helpful exercise. I was a bit worried that being the contact person would mean journalists calling me at all hours of the day and night for months; this turned out not to be the case. In fact, one journalist got in touch, from Inside Higher Ed, which led to an article (https://www.insidehighered.com/ news/2017/07/31/math-journal-editors-resign-start-rival- open-access-journal) giving a pretty clear and accurate account of what had happened. On the whole, I would say talking to the media was less of a big deal and less stressful than I had imagined.

\section{Afterword (Mark C. Wilson)}

In the case of Algebraic Combinatorics, it is already clear that it is a success and is the true successor to the journal founded in 1992 by Chris Godsil, Ian Goulden and David Jackson. More details behind the critical claims made above about the expertise of the current JACO boards can be found at http://mcw.blogs.auckland.ac.nz/2018/04/19/ alco-vs-jaco-a-stark-comparison/.

Since the start of 2018, a new organisation - the Free Journal Network (FJN) https://freejournals.org - has been created. It is intended to promote and nurture Fair OA-compliant journals and now has 24 members in mathematics, including Algebraic Combinatorics. I am on the steering committee.

I urge all editors of subscription journals to think hard about their responsibilities to the research community and the wider society and to contact MathOA to discuss flipping their journals. Also, I urge all mathematicians to support journals run according to the Fair Open Access model (e.g. members of FJN) and not contribute their volunteer labour to journals that transfer public money to private corporations while providing inferior service. Finally, all mathematicians are welcome to contribute to the discussion/action forum https://publishing-reform.gitlab.io/. 